1 Fundação Oswaldo Cruz (Fiocruz), Escola Politécnica de Saúde Joaquim Venâncio (EPSJV)

- Rio de Janeiro (RJ), Brasil. michelenantunes@gmail.

com

2 Universidade Federal do Espírito Santo (Ufes) Vitória (ES), Brasil.

\section{Comunicação rizomática: reflexões sobre os movimentos de resistência em tempos da Covid-19}

\author{
Rhizomatic communication: reflections on resistance movements in \\ Covid-19 times
}

Michele Nacif Antunes ${ }^{1}$, Jandesson Mendes Coqueiro²

DOI: 10.1590/0103-1104202213214

RESUMO Historicamente, o modelo de comunicação de risco e de emergência em saúde pública tem acontecido de forma hierárquica, menos cooperativa e democrática. Entretanto, em se tratando da pandemia da Covid-19, é possível observar que a garantia de uma comunicação universal, equânime e integral, para ampliação da participação cidadã nas políticas de saúde e na orientação do cuidado, não tem sido uma tarefa exclusiva das autoridades de saúde, dos especialistas, divulgadores científicos e de jornalistas, mas tem incorporado a participação de profissionais de saúde e de coletivos em diferentes territórios. O presente ensaio propõe discutir a comunicação rizomática no campo da saúde, destacando alguns movimentos de resistência, protagonistas nos processos comunicacionais, como as ações desenvolvidas pelos moradores do Complexo da Maré (RJ), povos do Xingu e de Rio Negro e comunidades quilombolas. As formas de comunicação rizomática desenvolvidas por esses movimentos, com utilização de podcasts, jornais, rádio, por exemplo, produzem novas formas de vida e novos modos de existência, por não terem um aspecto preestabelecido, no qual diferentes pontos se conectam no fluxo entre diversos atores, situações, elementos-chave, áreas e saberes em um caminho sistemático e criativo de pensar o mundo e suas complexidades, sustentando as diferenças e heterogeneidades dentro do território comunicacional.

PALAVRAS-CHAVE Covid-19. Pandemias. Comunicação em saúde.

\begin{abstract}
Historically, the public health risk and emergency communication model has been hierarchical, less cooperative and democratic. However, when it comes to the Covid-19 pandemic, it is possible to observe that the guarantee of universal, equitable and integral communication, to expand citizen participation in health policies and in the guidance of care, has not been an exclusive task of the authorities, of health experts, science communicator and journalists, but it has incorporated the participation of health professionals and collectives in different territories. This essay proposes to discuss rhizomatic communication in the field of health, highlighting some resistance movements, protagonists in communication processes, such as the actions developed by the residents of Complexo da Maré (RJ), Xingu and Rio Negro peoples and quilombola communities. The forms of rhizomatic communication developed by these movements, using podcasts, newspapers, radio, for example, produce new forms of life and new modes of existence, as they do not have a pre-established aspect, in which different points connect in the flow between different factors, situations, key elements, areas and knowledge in a systematic and creative way of thinking about the world and its complexities, sustaining as differences and heterogeneities within the communicational territory.
\end{abstract}

KEYWORDS Covid-19. Pandemics. Health communication. 


\section{Introdução}

O ano de 2020 começou com notícias que viraram o mundo de cabeça para baixo. Uma doença respiratória, que se iniciou com poucos casos registrados em Wuhan, na China, rapidamente se tornou a principal pauta na mídia internacional. O número de pessoas infectadas com o novo Coronavírus aumentou exponencialmente, e, em poucos meses, a Organização Mundial da Saúde (OMS) declarou emergência mundial em saúde.

A pandemia da Covid-19, diante de sua complexidade, trouxe vários elementos complicadores: um agente infeccioso novo para cientistas e equipes de saúde, sobre o qual pouco se sabia, mundo altamente conectado, excesso de informação e dificuldade de identificar fontes e dados confiáveis, o desfecho da pandemia com forte dependência das decisões tomadas por autoridades e cidadãos. Assim, informar a população sobre os riscos à saúde apresentados pela Covid-19 nunca foi tão importante quanto outras medidas de proteção'. No contexto pandêmico, cada vez mais, divulgar informações precisas e confiáveis permite que pessoas tomem decisões conscientes e adotem comportamentos positivos para cuidar de si e do outro.

Entretanto, a resposta ao coronavírus foi acompanhada por uma abundância excessiva de desinformação, que se espalhou rapidamente pelas plataformas de mídia social e outros meios de comunicação. Nesse novo cenário, apresentou-se uma imensa quantidade de informação acessível que pode afetar e alterar a compreensão e possíveis ações, tanto de maneira positiva quanto negativa.

Em um momento de surgimento de uma nova pandemia, os divulgadores de ciência e comunicadores precisam agir com responsabilidade, para disseminar informação clara e fundamentada, sem promover insegurança e pânico. Os meios de comunicação de massa são importantes veículos de informação em situações de risco e emergências, especialmente pelo seu grande alcance. Entretanto, cada vez mais, a atuação das equipes de comunicação de organizações de pesquisa e até a ação individual de cientistas e divulgadores podem ganhar grandes proporções na internet, em especial, nas redes sociais ${ }^{1}$.

Existe um conjunto de manuais e diretrizes com as melhores práticas para se comunicar com o público durante emergências de saúde pública. As diretrizes da $\mathrm{OMS}^{2}$, por exemplo, consistem em cinco princípios para orientar a comunicação durante surtos e outras emergências: construir confiança, anunciar cedo, ser transparente, respeitar as preocupações públicas e planejar com antecedência. Entretanto, a partir da experiência da recente epidemia de H1N1 e, recentemente, da Covid-19, fica evidente que o controle e a comunicação de surtos raramente são um processo simples no que diz respeito à confiança do público e à transmissão da informação de forma objetiva e transparente.

Muitos avanços foram feitos nas teorias e nos modelos de comunicação de risco e de crise e, especificamente, na comunicação das doenças infecciosas emergentes. Embora o consenso seja que as teorias e os modelos são atualizados e relevantes, na prática, o fluxo de informação permanece unilateral, linear, assumindo que a mensagem é projetada do remetente para o destinatário, sem qualquer possibilidade de feedback. Esse recurso reflete uma noção ultrapassada de papéis estáveis e imutáveis na comunicação ${ }^{3}$.

A maioria das organizações científicas e do campo da saúde desenvolve a comunicação em uma estrutura basicamente hierárquica e muito menos cooperativa e democrática. As organizações devem envolver o público nas redes sociais com base na abordagem participativa e considerar o público como parceiro, aquele que pode trabalhar juntamente com as organizações para desenvolver um campo mais aberto e inovador, promovendo projetos de ciência cidadã on-line. Somente aqueles que estão inseridos nos contextos locais podem contribuir para as organizações adaptarem suas mensagens de acordo com os contextos socioeconômicos, culturais, educacionais, entre outros ${ }^{4}$. 
Assim, é primordial a superação dessas deficiências, englobando novas tecnologias de comunicação. Cada vez mais, as mídias sociais desempenham um papel importante na disseminação da informação e, muitas vezes, da desinformação durante qualquer crise ou emergência. É fato que os avanços tecnológicos transformaram o modo como as organizações de saúde pública veem a informação e a disseminam às comunidades afetadas durante emergências, interagindo com elas. Assim, os comunicadores de risco e emergências devem considerar como potencializar o uso das novas tecnologias de comunicação no enfrentamento da situação. Da mesma forma, há um novo reposicionamento do público como participante ativo, que é facilitado por novas tecnologias móveis, especialmente smartphones, redes sociais e ferramentas disponíveis na internet ${ }^{5}$.

Em suma, o modelo atual adotado pela comunicação de risco e de emergências em saúde pública, como na pandemia da Covid-19, aponta para a necessidade de mudanças que incorporem novas estratégias e práticas que levem em conta os diversificados territórios, cenários, contextos e os processos sociais existentes. Assim, como afirma Sodré6, é necessário pensar a comunicação sob o ângulo de uma transcendência. A transcendência do diálogo, não como mero intercâmbio de palavras, mas como ação de fazer ponte entre as diferenças, em uma ação modeladora e um processo de colocar diferenças em comum, sem que processo e ação possam ser considerados arbitrários por parte dos indivíduos ${ }^{6}$.

Durante a pandemia da Covid-19, foi possível observar que a garantia de uma comunicação universal, equânime e integral7 para ampliação da participação cidadã nas políticas de saúde e na orientação do cuidado não tem sido uma tarefa exclusiva das organizações, autoridades de saúde, especialistas, divulgadores científicos e de jornalistas, mas tem incorporado, também, a participação de profissionais de saúde e de coletivos em diferentes territórios.

Dessa forma, fica a pergunta: é possível outra forma de comunicação de risco e emergências em saúde pública no Brasil? Uma comunicação que esteja ancorada na integração e articulação de diversos atores no enfrentamento do risco? Uma comunicação que não seja ancorada em relações hierárquicas e lineares? Uma comunicação em que o público assuma um lugar de protagonismo e não periférico?

Assim, a partir dessas questões e diante dos desafios informacionais impostos pela pandemia da Covid-19, o presente ensaio propõe discutir a comunicação rizomática no campo da saúde, destacando alguns movimentos de resistência como protagonistas nos processos comunicacionais, tendo os diferentes territórios como disparadores de práticas e estratégias de comunicação.

\section{O rizoma deleuze- guattariano: apontamentos}

A comunicação rizomática, que nos propomos a discutir aqui, surge por pensar no protagonismo da população frente à mídia e a outros processos comunicacionais, configurando-se um movimento de resistência que inventa, produz novos modos de existência e viver e que são amorfas, não possuindo formas determinadas para emergir.

O conceito de Rizoma, em uma perspectiva filosófica, cunhado por Deleuze e Guattari ${ }^{8}$, diz respeito às perspectivas amplas para a compreensão da vida, indo em direção à complexidade que lhe é inerente. Esses autores são considerados filósofos da diferença, da multiplicidade e/ou da imanência, na qual compreendem a construção do conhecimento como um devir, ou seja, renunciam-se à noção de conceitos como certezas sobre algo e identificam que o conhecimento é uma produção genuinamente circunstancial8.

As produções conjuntas entre Deleuze e Guattari se iniciaram com a escrita da clássica obra 'O Anti-Édipo'8 (primeira edição publicada na França, em 1972), em que os autores discutiram a potência do desejo, colocando em xeque o modo como psiquiatria e psicanálise 
trabalham o tema. Depois seguiram com as obras 'Kafka: por uma literatura menor'10 (publicado em 1975 e 1976), trazendo questões a respeito da literatura menor como expressão dos agenciamentos e desejos coletivos, e 'Mil Platôs'11 (publicado em 1980), que propõe uma revisão das estruturas de pensamento a partir da Terra e abre novas perspectivas para a concepção do ser humano, do capitalismo, do Estado e dos modos de vida em sociedade; e encerraram com a obra ' $\mathrm{O}$ que é filosofia?'12, discutindo a produção de conceitos, algo que eles defendem ser o papel da filosofia e que acabou sendo a marca registrada desses autores. Dessa forma, os conceitos demonstram tentativas de compreensão dos acontecimentos e das circunstâncias, e não uma busca da definição das coisas como elas são (conceito como essência) ${ }^{9}$.

Além da criação de conceitos, outra característica fundamental na escrita de Deleuze e Guattari era a interface constante com diversas áreas, como literatura, música, biologia, cinema, educação, entre outras. Essa conexão de diferentes saberes tornou-se, para os autores, um caminho sistemático e criativo de pensar a complexidade do mundo, baseado em diferenças e heterogeneidades 9 .

Levando em consideração essa interface constante com diversas áreas em que Deleuze e Guattari trabalhavam, cabe mencionar que o próprio conceito de Rizoma é uma referência clara dessa imbricação de diferentes saberes, pois, citada já no primeiro capítulo da obra 'Mil Platôs'1", é um termo oriundo da botânica, consistindo em hastes subterrâneas com ramificações de todos os lados, como os tubérculos e os bulbos. Do ponto de vista filosófico, o rizoma é compreendido como uma forma da vida, no sentido mais ampliado, sob forma de conexões, sem início ou fim, entremeadas por segmentaridades, linhas, intensidades e estratos ${ }^{11}$.

Para melhor definição do Rizoma, Deleuze e Guattari apresentaram seis princípios norteadores dessa teoria, sendo que o primeiro e o segundo remetem à ideia de que no rizoma todos os pontos podem ser conectados, sem referência central ou hierárquica (princípio da conexão), associando-se ao princípio da heterogeneidade, caracterizado pela noção de uma realidade complexa em que diferentes estatutos de algo coexistem em movimento, que formam conexões múltiplas e diversas. Dessa forma, não se pode refletir em uma coisa ou outra, mas uma coisa e outra. Um exemplo dessas múltiplas conexões se apresenta através da análise da língua, que não se restringe ao que se diz e aos seus significados expressos, mas carrega consigo formas de agenciamentos e variáveis de poder sociais particulares"1.

Quanto ao terceiro princípio, o da multiplicidade, relacionado diretamente com os anteriores, refere-se ao abandono do pensamento dicotômico, que vem determinando a separação binária entre polos como objeto e sujeito, homem e mulher, bem e mal. Essas formas de compreender a vida, para Deleuze e Guattari1", não são capazes de traduzi-la, uma vez que são inúmeras as linhas e conexões que se cruzam, são movimentos, agenciamentos "crescimento das dimensões numa multiplicidade que muda necessariamente de natureza à medida que ela aumenta suas conexões"11(17).

O quarto princípio se constitui em ruptura assignificante, que define a liberdade que o rizoma tem de romper qualquer dos seus pontos, assim como de poder retomar o seu processo. Esse sistema, marcado por conexões, heterogeneidade e multiplicidade, compreende e abarca o diferente, havendo sempre espaço para reconfiguração. Não existe perenidade, mas, ao contrário, prevalência do temporário, como, por exemplo, o bom e o mau são somente produto de uma seleção temporária e ativa a ser recomeçada ${ }^{11}$.

Já o quinto e o sexto princípios de um sistema rizomático se configuram como a cartografia e a decalcomania na qual "um rizoma não pode ser justificado por nenhum modelo estrutural ou gerativo. Ele é estranho a qualquer ideia de eixo genético ou de estrutura profunda"11(21).

Dessa maneira, o rizoma DeleuzeGuattariano não tem começo nem fim, ele se encontra sempre no meio, entre as coisas. A 
árvore determina o verbo 'ser', mas o rizoma tem como disposição a conjunção 'e... e... e...'. Existe nessa conjunção uma força capaz de movimentar e desenraizar o verbo ser, na qual o meio não é uma média, mas o lugar onde as coisas adquirem velocidade ${ }^{11}$.

\section{Reflexões sobre a comunicação rizomática e os movimentos de resistência}

Atualmente, tem se verificado que a sociedade participa do processo de comunicação de diversas formas e em espaços diferentes daqueles já institucionalizados, como as redações de jornais, por exemplo. Isso tem provocado interferências nos modos de se pensar a comunicação social, pois essas ações, empreendidas pela sociedade, materializam-se nas mais diversas formas e podem ser tomadas como movimentos de resistência. Essas mobilizações, conforme posto por Foucault ${ }^{13}$, disseminam-se com mais ou menos densidade no espaço e no tempo, por vezes, provocando o levantamento de pessoas ou grupos de maneira definitiva, estimulando certos momentos da vida, alguns tipos de comportamentos e algumas partes do corpo. É visto, mais comumente, como ponto de resistência transitório e móvel, que inclui na sociedade clivagens que deslocam unidades e suscitam reagrupamentos, percorrem os próprios indivíduos, remodelando-os, traçando neles, em seu corpo e alma, regiões irredutíveis.

Os movimentos de resistência se configuram como uma criação social de outras possibilidades de vida, empreendidas sem uma intenção preestabelecida, ou seja, não existe um planejamento prévio do agir ${ }^{14}$. Entretanto, Romagnoli15 explica que, se existe resistência, é porque não houve captura das forças inventivas da vida, isto é, se há produção de modos novos de viver, é porque existem movimentos de resistência.
Vale acrescentar, ainda, que as resistências colocam em questionamento a forma preestabelecida e hegemônica das instituições, como a mídia, por exemplo. Nesse contexto, as instituições, segundo Baremblitt" ${ }^{16}$, são árvores de deliberação lógicas que moderam as atividades humanas, apresentando o que é permitido, proibido e indiferente. As instituições são compreendidas por um movimento que as gera (instituinte), um resultado (instituído) e um processo (institucionalização). Para realizar concretamente sua função regulamentadora, as instituições materializam-se em organizações e estabelecimentos.

Em se tratando do campo da comunicação social, os movimentos de resistência colocam em questionamento a forma preestabelecida de difundir informações imposta pela mídia, sendo uma maneira de a população se comunicar de forma alternativa aos meios de comunicação hegemônicos. Com isso, refletir sobre o processo de comunicação e os movimentos de resistência para além da mídia hegemônica representa pensar esse processo como ação instituinte, ou seja, processo mobilizado por forças produtivo-desejante-revolucionárias que tem tendência a criar instituições ou modificá-las como parte do devir potências ${ }^{16}$.

Essas formas de comunicação que se apresentam nos movimentos de resistência, produzem novas formas de vida e novos modos de existência, são denominadas comunicação rizomática, conforme figura 1, por não terem um aspecto preestabelecido, onde diferentes pontos se conectam no fluxo entre diversos atores (mídia, movimentos sociais, líderes de opinião, organizações governamentais, indústria farmacêutica e comércio), situações (desastres, epidemias, pandemias e emergências), elementos-chave (ética, transparência, literacia, disputas, integralidade e equidade), áreas e saberes (comunicação, saúde e educação, por exemplo), em um caminho sistemático e criativo de pensar o mundo e suas complexidades, sustentando as diferenças e heterogeneidades dentro do território comunicacional. Esse fluxo acontece de forma sistemática, e cada 
item pode ganhar um destaque maior a depender do contexto histórico vivido, do ângulo analisado e da perspectiva de qual ponto se vai analisar o processo comunicacional.

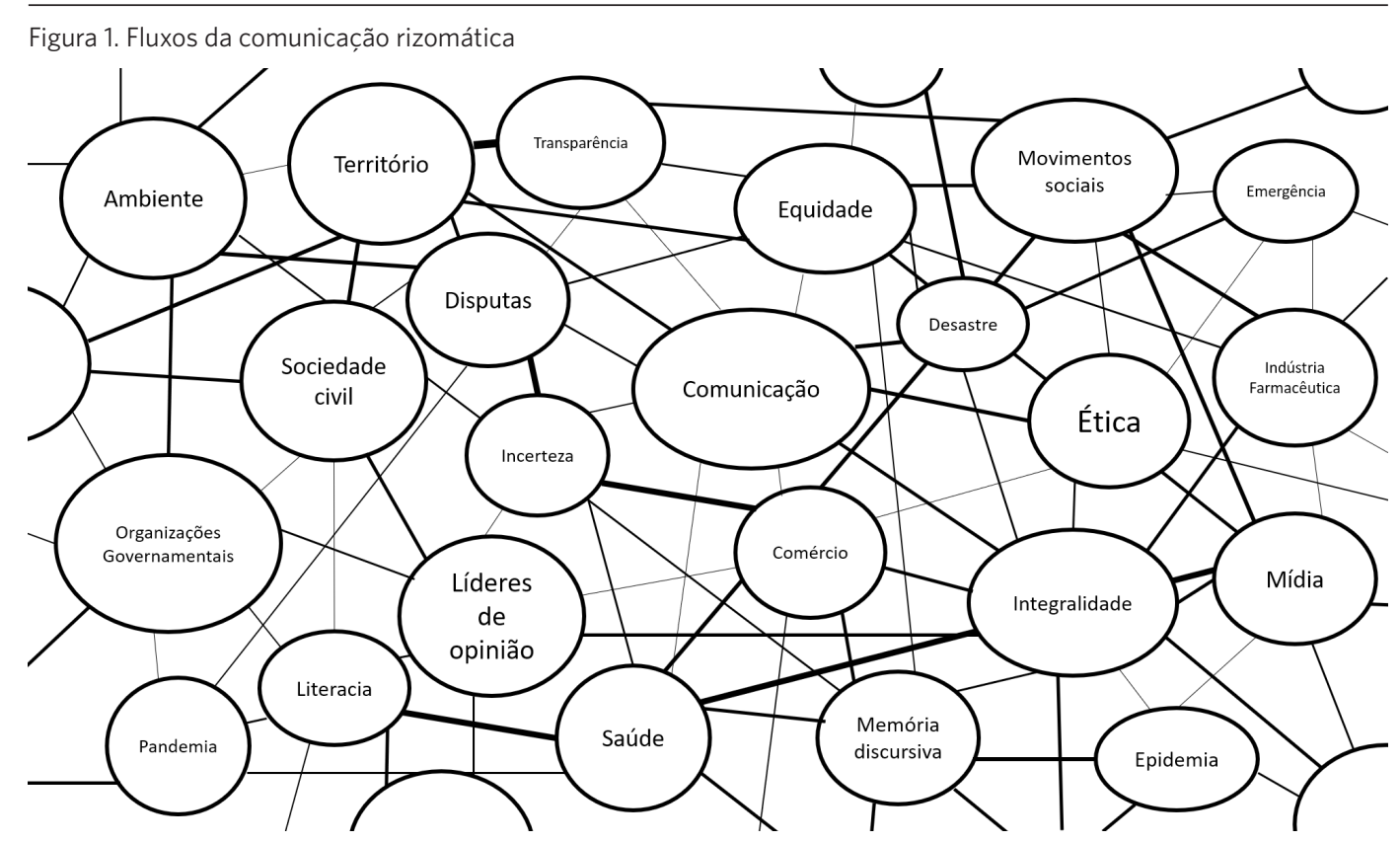

Fonte: elaboração própria.

Nesse processo de comunicação, o fluxo rizomático é formado por linhas que se conectam e colocam em evidência as multiplicidades de saberes envolvidos no modo de comunicar rizomaticamente, tendo o público como um grande aliado na produção de conteúdo sobre os mais diversos assuntos e moldando, também, a forma com que as notícias são produzidas pela mídia e por organizações públicas de saúde. Dessa maneira, tem-se como exemplo o processo comunicacional desenvolvido pelos moradores do Complexo da Maré (RJ), que usam os meios comunitários para se informar durante a pandemia e iniciativas no Xingu e Rio Negro, que buscam levar informações e alertas sobre a pandemia para povos indígenas e comunidades tradicionais.

Com a utilização de podcast, jornal e 'rádio no poste', os moderadores do Complexo da Maré - território composto por seis comunidades, localizado na Zona Norte do Rio de
Janeiro (RJ), com população de 64 mil habitantes - têm realizado o processo de comunicação rizomática em tempos de pandemia da Covid-19.

O podcast 'Maré em Tempos de Coronavírus', também conhecido popularmente como 'audião no zap', é uma iniciativa criada para informar a população sobre o enfrentamento da Covid-19 na comunidade. Como a população não tem acesso à internet de qualidade, o áudio é divulgado em forma de 'mensagem de voz' em aplicativos como o WhatsApp, que é acessível e requer poucos recursos nos celulares, além da distribuição nas plataformas digitais específicas de podcast. Já o jornal 'Maré de notícias', que busca o enfrentamento das notícias falsas (fake news), é distribuído mensalmente, e algumas edições foram publicadas em formato on-line para evitar contato físico e uma possível propagação da doença. A rádio comunitária, conhecida como 'rádio no poste', 
trabalha com músicas diversificadas, anúncios, informação de utilidade pública para a comunidade e, com o avanço da pandemia, também atuou em divulgações sobre o assunto ${ }^{17}$.

Os processos comunicacionais promovidos pelos povos do Xingu e Rio Negro durante a pandemia da Covid-19 funcionam através de gravação de podcasts e criação de informativos em sua língua materna, o que proporciona melhor compreensão da informação pelos povos indígenas. Além disso, são produzidos vídeos, cards, áudios e informativos com dados atualizados e orientações de prevenção, que são divulgados nas aldeias, comunidades e cidades pelas redes sociais e aplicativos de mensagem. Entretanto, em lugares sem disponibilidade de internet, o que prevalece são as informações disseminadas pela rádio. Para isso, os profissionais de saúde, educadores e organizações, como a Fundação Nacional do Índio (Funai), Associação Terra Indígena Xingu (Atix) e Rede Xingu+, enviam radiogramas sobre medidas preventivas da Covid-19, e, quando chegam novidades sobre o assunto, a comunidade liga a rádio em um mesmo horário para receber orientações e fazer perguntas ${ }^{18}$.

Esses movimentos são considerados comunicações rizomáticas, por se apresentarem como amorfas, imprevisíveis e inventivas. Eles colocam em julgamento as formas com que os meios de comunicação hegemônicos estruturam suas notícias, mas com a intenção de criar fluxos que possam fazer emergir o novo e potencializar as formas de vida em cada uma das comunidades existentes.

Dessa forma, a comunidade inserida nesse processo de comunicação rizomática pode ser entendida, no contexto de implementação das ações próximas da realidade de cada território, como Grupo Sujeito ${ }^{16}$, isto é, um coletivo que se constitui como uma utopia ativa, capaz de gerar suas próprias normas - como realização de pautas com assuntos destinados ao local, conforme visto pela comunidade do Complexo da Maré, e na produção de informação na língua nativa, como acontece entre os povos do Xingu e Rio Negro. Assim, eles se afastaram da conjuntura de um Grupo Sujeitado, ou seja, alienados em objetivos, procedimentos e normas que lhes são impostas, como, por exemplo, ouvir de forma passiva uma informação na rádio sem poder esclarecer dúvidas sobre $\mathrm{o}$ assunto ou aceitando passivamente as informações que são impostas sem vinculação com a realidade de cada comunidade.

Vale destacar que, ao refletir sobre grupo sujeito e sujeitado, a comunicação rizomática apresenta pontos de convergência e divergência com as características da comunicação comunitária. A convergência se dá no sentido de que a comunicação comunitária é entendida como um processo em que todo receptor de mensagens dos meios de comunicação tem o potencial de se tornar sujeito da comunicação, um emissor ${ }^{19}$. Entretanto, os meios de comunicação nos territórios, embora abordem as diferentes questões locais, podem não ser caracterizados como comunitários. Isso acontece quando essa comunicação é produzida e exercida reproduzindo os padrões e interesses da mídia hegemônica, ainda fechada à participação ampliada do cidadão ${ }^{19}$. Dessa forma, na comunicação rizomática, pode haver, também, uma ruptura com essa concepção de comunicação comunitária que é imposta aos territórios.

É importante acrescentar, também, que, para a comunicação rizomática nesses movimentos de resistência, os podcasts, jornais e rádio têm se configurado como um agenciamento ${ }^{16}$, que, também chamados de dispositivos, são uma montagem produtora de inovações que gera acontecimentos (algo imprevisível) e devires, ignorando, muitas vezes, os limites constituídos das entidades molares (conservadoras), como a mídia tradicional. Esses dispositivos, quando utilizados por esses coletivos, podem gerar diferença absoluta e produzir realidades revolucionárias, na medida em que potencializam as vozes dos sujeitos, muitas vezes, pouco ouvidas pelas organizações de saúde, pesquisas etc.

Nesse cenário, cabe ressaltar que a comunicação rizomática também se estabeleceu entre os coletivos, muitas vezes, como resposta aos 
atravessamentos sofridos durante a pandemia da Covid-19. Segundo Baremblitt ${ }^{16}$, um atravessamento se configura como articulação, entrelaçamento e interpenetração de articulação conservadora, que serve de dominação, exploração e mistificação, apresentadas como necessárias e benéficas.

Um dos atravessamentos identificados durante a pandemia da Covid-19 foi a invisibilidade da doença em territórios quilombolas ${ }^{20}$. Os dados nessa população são subnotificados, e o Ministério da Saúde tem negligenciado atenção específica às populações negras, uma vez que o quesito raça/cor não foi elegível para análise de situação epidemiológica da Covid-19 nos primeiros boletins epidemiológicos ${ }^{20}$, e a incorporação dessas informações como categoria de análise se deu após posicionamentos do Grupo de Trabalho (GT) Racismo e Saúde, da Coalizão Negra e da Sociedade Brasileira de Médicos de Família e Comunidade ${ }^{21}$.

Esse atravessamento enfrentado pela população quilombola fez com que a Coordenação Nacional de Articulação das Comunidades Negras Rurais Quilombolas (Conaq) e o Instituto Socioambiental criassem o 'Observatório da Covid-19 nos Quilombos', com objetivo de monitorar casos confirmados e óbitos decorrentes da Covid-19 entre quilombolas. A plataforma é atualizada com informações enviadas por pontos focais regionais da Conaq, que acompanham a situação de casos confirmados e óbitos junto às comunidades e organizações locais nos territórios. Com as informações atualizadas, a sociedade brasileira e, em especial, as comunidades quilombolas dispõem de mais informações para exigir providências do Estado, para que tome medidas em defesa da vida das famílias quilombolas, uma vez que a maioria dos territórios está localizada distante de hospitais estruturados e perto de municípios com sistema de saúde fragilizado ${ }^{22}$.

No processo de comunicação rizomática, os movimentos de resistência, como os apresentados pela comunidade Complexo da Maré, povos do Xingu e Rio Negro e da comunidade quilombola, configuram-se como fluxos desviantes ${ }^{16}$, ou seja, coletivos que questionam o instituído (o Estado e a mídia tradicional, por exemplo), protagonizando um afastamento da linha condutora hegemônica da organização, tornando-se o gérmen de um processo produtivo-desejante-revolucionário.

Além disso, o processo de comunicação rizomática nesses movimentos de resistência se apresenta como uma produção desejante, uma produção do que é imanente ao desejo, sendo que o desejo se configura como não representacional; é real-e-virtual, situado no plano virtual à espera de abertura e conexões para poder operar no plano de objetos e modos de subjetivação $0^{\mathbf{2 3}}$.

Outrossim, essa comunicação rizomática é uma das formas de os indivíduos reconhecerem suas opiniões, construírem fontes de formação de crenças e atitudes, sendo capazes, desse modo, de apresentar o pensamento coletivo de uma determinada população. Portanto, os processos comunicacionais, como a forma rizomática, devem ser explorados, para que aconteça uma reflexão a respeito das ações instituintes que vêm surgindo em vários territórios durante a pandemia da Covid-19, bem como uma análise da implicação - lugar que o indivíduo ocupa no mundo ${ }^{24}$ - dos sujeitos no processo de comunicação.

\section{Considerações finais: uma porta entreaberta}

Na contemporaneidade, os meios de comunicação, muitas vezes, assumem um papel centralizador na midiatização de riscos e emergências em saúde pública, de modo que podem influenciar o estabelecimento de crenças, opiniões e comportamentos. Essa centralidade dos meios de comunicação impulsiona as organizações de saúde a desenvolverem as estratégias comunicacionais em uma estrutura hierárquica, menos cooperativa e menos democrática.

Diante dos desafios informacionais da pandemia da Covid-19, foi possível observar diversos movimentos que potencializaram 
o protagonismo da população em resposta a essa centralidade da mídia e dos processos comunicacionais ancorados em relações hierárquicas e lineares, configurando-se um movimento de resistência que cria modos de viver e existir, não possuindo, dessa maneira, formas planejadas de revelar-se nos territórios.

$\mathrm{O}$ enfrentamento da pandemia apresentou, em cada território, diferentes desafios, de acordo com as carências e adversidades ali existentes, que foram potencializadas pelo acesso às tecnologias de informação e comunicação, por meio das quais os atores locais difundiram informações sobre o cuidado, fizeram denúncias e pedidos de apoio por intermédio de jornais, vídeos e áudios. $\mathrm{Na}$ perspectiva da comunicação rizomática, eles se aproximaram de características presentes em Grupos Sujeitos da comunicação e se afastaram do contexto de um Grupo Sujeitado, ou seja, alienado em objetivos, procedimentos e normas que lhes são impostas por Estado, mídia e organizações de saúde.

Além disso, é importante frisar que a comunicação rizomática implementada pelos coletivos do Complexo da Maré (RJ), dos povos indígenas do Xingu e Rio Negro e quilombolas nos tempos de pandemia da Covid-19 não é um caso isolado. Constantemente, outros movimentos, muitas vezes, sem visibilidade, surgem no sentido de criar o novo, potencializar as formas de existência em cada coletivo e lutar pelos desafios impostos pelas instituições opressoras. Além disso, a comunicação rizomática desses e de outros coletivos está em constante rompimento, formando outras conexões, uma vez que os desafios enfrentados por eles são contínuos e não se limitam à pandemia da Covid-19.
A partir do que foi discutido, advoga-se que o diálogo eficaz com o público durante emergências sanitárias pode ser potencializado pelas organizações de saúde a partir da compreensão da comunicação rizomática, em que diferentes pontos se conectam no fluxo entre diversos atores, situações, elementos-chave, áreas e saberes em um caminho sistemático e criativo de pensar o mundo e suas complexidades, sustentando as diferenças e heterogeneidades dentro do território comunicacional.

Assim, ao envolver o público com base na abordagem participativa e o considerando como parceiro, ou seja, aquele que pode trabalhar em conjunto para o desenvolvimento de estratégias comunicacionais voltadas para territórios específicos, as organizações de pesquisa estarão, também, promovendo uma ciência mais aberta, colaborativa e cidadã, que atue mobilizada por forças produtivo-desejante-revolucionárias no fortalecimento do devir-potência das diversas forma de viver da população.

Neste momento, finalizamos, mas com a porta entreaberta para que novos estudos sejam realizados com vistas a problematizar as formas de comunicação em tempos de risco e emergência pública, colocando em destaque o protagonismo dos movimentos de resistência e de coletivos no enfrentamento dos desafios encontrados.

\section{Colaboradores}

Antunes MN (0000-0001-8500-8930)* e Coqueiro JM (0000-0002-5321-5174)* contribuíram igualmente para a elaboração do manuscrito. 


\section{Referências}

1. Chagas C, Massarani L. Manual de sobrevivência para divulgar ciência e saúde. Rio de Janeiro: Editora Fiocruz; 2020. 152 p.

2. Organização Mundial da Saúde. Outbreak communication. best practices for communicating with the public during an outbreak. Geneva: World Health Organization; 2004.

3. Antunes MN. Comunicando o Risco: um olhar sobre a epidemia de zika. Vitória: Universidade Federal do Espírito Santo; 2018. [acesso em 2021 abr 3]. Disponível em: http://repositorio.ufes.br/handle/10/10334.

4. Gesser-Edelsburg A. How to Make Health and Risk Communication on Social Media More "Social” During COVID-19. Risk Manag Healthc Policy. 2021 [acesso em 2021 abr 3]; (14):3523-40. Disponível em: https://www.dovepress.com/how-to-make-health-and-risk-communication-on-social-media-more-social--peer-reviewed-fulltext-article-RMHP.

5. Gesser-Edelsburg A, Shir-Raz Y. Risk communication and infectious diseases in an age of digital media. Routledge: Risk Communication and Infectious Diseases in an Age of Digital Media; 2016.

6. Sodré M. A ciência do comum. Notas para o método comunicacional. Petrópolis: Vozes; 2014.

7. Araújo IS, Cardoso JM. Comunicação e saúde. Comunicação e saúde. Editora Fiocruz; 2007.

8. Deleuze G, Guattari F. O anti-Édipo: capitalismo e esquizofrenia. São Paulo: Editora 34; 2011.

9. Barreto RDO, Carreieri ADP, Romagnoli RC. O rizoma deleuze-guattariano nas pesquisas em Estudos Organizacionais. Cad EBAPEBR. 2020 [acesso em 2021 abr 3]; 18(1):47-60. Disponível em: http://www.scielo.br/scielo.php?script=sci_arttext\&amp;pid=S1679-39512020000100047\&amp;tlng=pt.

10. Deleuze G. Kafka: por uma literatura menor. Rio de Janeiro: Imago; 1977.
11. Deleuze G, Guattari F. Mil Platôs. 2. ed. São Paulo: Editora 34; 1995.

12. Deleuze G, Guattari F. O que é a filosofia? 3. ed. São Paulo: Editora 34; 1995.

13. Foucault M. História da sexualidade: a vontade de saber. 17. ed. São Paulo: Graal; 2006.

14. Oliveira S. Micropolitica do fracasso escolar: uma tentativa de aliança com o invisível. Vitória: Universidade Federal do Espírito Santo; 2001.

15. Romagnoli RC, Paulon SM, Amorim AKMA, et al. Por uma clínica da resistência: experimentações desinstitucionalizantes em tempos de biopolítica. Interface - Comun. Saúde, Educ. 2009 [acesso em 2021 abr 4]; 13(30):199-207. Disponível em: http://www.scielo.br/scielo.php?script=sci_arttext\&amp;pid=S1414$-32832009000300016 \& a m p ; l n g=p t \& a m p ; t \operatorname{lng}=$ pt.

16. Baremblitt G. Compêndio de Análise Institucional e outras correntes: teoria e prática. 6. ed. Belo Horizonte: FGC/IFG; 2012.

17. Rodrigues M. Podcast, jornal e "rádio de poste": moradores da Maré usam meios comunitários para se informar durante pandemia. G1. 2020 jun 3. [acesso em 2021 out 7]. Disponível em: https://gl.globo.com/rj/ rio-de-janeiro/noticia/2020/06/03/podcast-jornal-e-radio-de-poste-moradores-da-mare-usam-meios-comunitarios-para-se-informar-durante-pandemia. ghtml.

18. Instituto Socioambiental. Do rádio à internet, indígenas e ribeirinhos usam a comunicação para enfrentar Covid-19. [acesso em 2021 out 7]. Disponível em: https://www.socioambiental.org/pt-br/noticias-socioambientais/do-radio-a-internet-indigenas-e-ribeirinhos-usam-a-comunicacao-para-enfrentar-covid-19.

19. Krohling P, Cicilia M. Conceitos de comunicação popular, alternativa e comunitária revisitados. Reelaborações no setor. Palabra Clave. 2008 [acesso em 2021 out 7]; 11(2):367-379. Disponível em: 
http://www.scielo.org.co/scielo.php?script=sci arttext\&amp;pid=S0122-82852008000200014\&am $\mathrm{p} ;$ lng=en\&amp;nrm=iso.

20. Quilombo sem COVID-19. Observatório da Covid-19 nos Quilombos. [acesso em 2021 out 7]. Disponível em: https://quilombosemcovid19.org/.

21. Santos MPA, Nery JS, Goes EF, et al. População negra e Covid-19: reflexões sobre racismo e saúde. Est. Avanç. 2020 [acesso em: 2021 out 7]; 34(99):225-44. Disponível em: http://www.scielo. br/scielo.php?script=sci_arttext\&amp;pid=S0103$-40142020000200225 \& a m p ; t \operatorname{lng}=$ pt.

22. Instituto Socioambiental. Conaq e ISA lançam o ‘Observatório da Covid-19 nos Quilombos’. 2020. [acesso em 2021 out 7]. Disponível em: https://www.socioambiental.org/pt-br/noticias-socioambientais/conaq-e-isa-lancam-o-observatorio-da-covid-19-nos-quilombos.

23. Guattari F. Micropolítica: cartografias do desejo. 7. ed. Petrópolis: Vozes; 2005.

24. Lourau R. René Lourau na UERJ - Análise Institucional e Práticas de Pesquisa. Rio de Janeiro: Eduerj; 1993.

Recebido em 14/10/2021

Aprovado em 07/12/2021

Conflito de interesses: inexistente

Suporte financeiro: não houve 